\title{
Development of Dispersion Models for the Simulation of Fluid Catalytic Cracking of Vacuum Gas Oil in Riser Reactor
}

\author{
Kenneth Kekpugile Dagde \\ Department of Chemical/Petrochemical Engineering, Rivers State University, Port Harcourt, Nigeria \\ Email: dagde.kenneth@ust.edu.ng
}

How to cite this paper: Dagde, K.K. (2018) Development of Dispersion Models for the Simulation of Fluid Catalytic Cracking of Vacuum Gas Oil in Riser Reactor. Advances in Chemical Engineering and Science, 8, 298-310.

https://doi.org/10.4236/aces.2018.84021

Received: April 18, 2018

Accepted: October 23, 2018

Published: October 26, 2018

Copyright $\odot 2018$ by author and Scientific Research Publishing Inc. This work is licensed under the Creative Commons Attribution International License (CC BY 4.0).

http://creativecommons.org/licenses/by/4.0/

\begin{abstract}
Dispersion models for the simulation of an industrial Fluid Catalytic Cracking Riser Reactor have been developed. The models were developed based on the principle of conservation of mass and energy on the reacting species due to bulk flow and axial dispersion. The four-lump kinetic scheme was used to describe the cracking reactions occurring in the reactor. The model equations were a set of parabolic Ordinary Differential Equations which were reduced to first order differential equations by appropriate substitutions and integrated numerically using $4^{\text {th }}$ order Runge Kutta algorithm using Visual Basic 6.0. Results obtained showed a maximum percentage deviation ranging from $0.31 \%$ to $5.7 \%$ between model predictions and industrial plant data indicating reasonable agreement. Simulation of model at various operating parameters gave optimum gasoline yield of $45.6 \%$ of the most significant variable of temperature $(658 \mathrm{~K})$, superficial velocity $(0.1 \mathrm{~m} / \mathrm{s})$, catalyst to gas oil ratio (7.0) and diffusion coefficient of $0.23 \mathrm{~m}^{2} / \mathrm{s}$.
\end{abstract}

\section{Keywords}

Modelling and Simulation, Axial Dispersion, Vacuum Gas Oil, Riser Reactor, Visual Basic 6.0

\section{Introduction}

The Fluid Catalytic Cracking Unit (FCCU) is a very important unit in the refinery. This unit is often referred to as the "cash cow" of all refining operations, since it cracks heavy residual stocks recovered from other refinery operations into more valuable hydrocarbons. Fluid catalytic cracking employs an extremely hot circulating fluidized bed catalyst to crack the high molecular weight hydro- 
carbons into low molecular weight hydrocarbons [1].

Circulating fluidized beds are especially useful in processes involving high gas and solids flux, and in catalytic reactions requiring quick catalyst regeneration [2]. Depending on the flow direction of the feed stream and catalyst bed, the circulating fluidized bed reactors are classified as: downer reactor-for downward flow, and riser reactor-for upward flow direction [3] [4]. Studies have shown that the downer is more efficient than the riser because both gas and solids flow downward in the same direction by gravity. The radial gas and solid flow structures are much more uniform in the downer, than the riser. Many studies have been carried out to help in the design and operation of fast fluidized bed reactions [5]. Among the many parameters of interest is the axial distribution of the cross-sectional averaged bed voidage, which is useful in understanding the gas and solids flow patterns in the bed. This parameter also provides essential information for optimal design and operation of a circulating fluidized bed reactor.

In the F.C.C.U., the atomized feed (vacuum gas oil) is sprayed into the reactor, where it comes in contacts with extremely hot fluidized bed of catalyst that supplies the heat required for the cracking reaction. The cracking process is endothermic and takes place in few seconds. The hot catalyst vaporizes the feed and catalyzes the cracking reactions that breakdown the high molecular weight oil into higher components, including; gasoline, liquefied petroleum gas (LPG), fuel gas and coke. The hydrocarbon mixture flows to the main fractionator via cyclones for separation into: fuel gas, LPG, gasoline, high cycle oil and main-column bottom (decanted oil). The spent catalyst is disengaged from the cracked hydrocarbon vapours and reactivated in a regenerator by burning the coke deposited on its active surface. This regeneration reaction is exothermic. Fernandes et al. [6] used a six-lump, one dimensional (1D) model to simulate the riser of an industrial FCCU. Their model predicted a gasoline yield of $48 \%$. However, the assumption of $1 \mathrm{D}$ plug flow and negligible dispersion by the authors oversimplified their models thereby undermining the accuracy of the predictions. [7] [8] [9] [10] used four-lump, 1D model in their investigations. Their models predicted the temperature drop along the riser reactor. The major limitation of their models was the assumption of negligible dispersion. A five-lump and six-lump reactions scheme were used by [11] [12]. The latter author also based their investigations on negligible dispersion which contradicts the basic principles of heterogeneous catalysis especially for porous catalyst such as the FCC zeolite catalyst. A one dimensional steady state model of an industrial riser reactor considering bulk flow and dispersion were presented in this study. A four-lump reaction scheme was used to model the FCC reactions [12]. Models were integrated numerically using a code written in Visual Basic 6.0 programming language. Data used for the simulation were sourced from an existing operational industrial plant and from literature.

\section{Dispersion Riser Reactor Model}

Figure 1 shows the hypothetical representation of the Fluid Catalytic cracking 


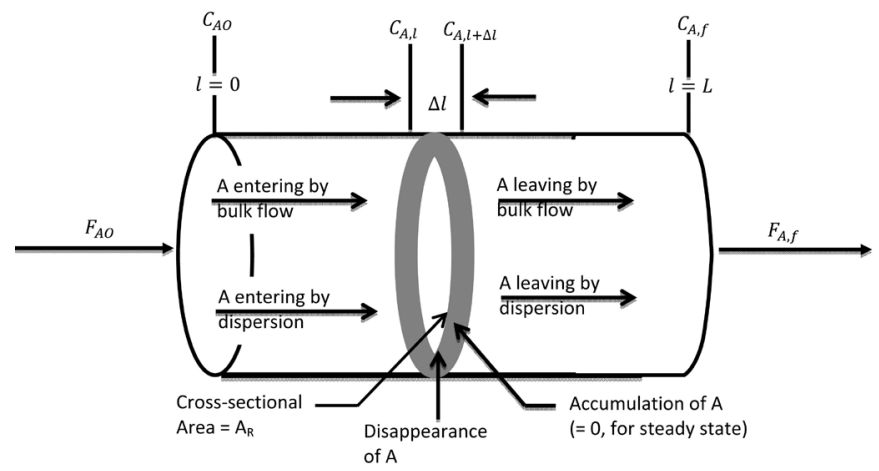

Figure 1. Hypothetical representation of a riser reactor in which reaction and dispersion are occurring simultaneously.

riser Reactor in which reactions and axial dispersion occurs. In developing model equations to investigate the catalytic cracking of vacuum gas oil in the reactor has led to a measure of axial dispersion characterized by a dimensionless group as $\frac{D}{u L}$. Where $\mathrm{F}_{\mathrm{Ao}} \& \mathrm{~F}_{\mathrm{Af}}$ are the initial and final flow rate, $\mathrm{C}_{\mathrm{Ao}} \& \mathrm{C}_{\mathrm{Af}}$ are the initial and final concentration, $L$ is the length, $u$ is the velocity and the application of fundamental quantities viz: mass and energy to obtain the state equations with respect to the differential element of volume as shown in Figure 1.

\subsection{Model Assumptions}

The following simplifying assumptions were made in the derivation of the mathematical model:

1) Axial dispersion is taken into consideration and catalyst particles have a uniform size in the given differential element. Both gas oil and gasoline have identical activity decay function, $\phi[7]$.

2) Constant superficial velocity, $u$ is assumed [13].

3) $C_{1}-C_{4}$ gases do not produce coke, and the coke content in the feed is negligible [8].

4) The mass and energy balance in the riser reactor are considered at quasi-steady state [8].

5) The cracking reactions are almost complete in the riser [10].

\subsection{Model Development}

Under these assumptions, the component mass balance for the mass concentrations due to bulk flow and axial dispersion and rate of depletion of the reacting species operating at steady state in the riser (plug-flow) reactor can be obtained as:

$$
u \frac{\mathrm{d} \rho_{A}}{\mathrm{~d} l}-D \frac{\mathrm{d}^{2} \rho_{A}}{\mathrm{~d} l^{2}}+\left(-r_{A}\right) \rho_{g R} \varepsilon=0
$$

A dimensionless catalyst bed height and residence time are defined as: $z=\frac{l}{L_{R}}$, and $\tau=\frac{L_{R}}{u}=\frac{V_{R}}{v_{o}}$, Equation (1) becomes; 


$$
\frac{\mathrm{d} \rho_{A}}{\mathrm{~d} z}-\frac{D}{u L_{R}} \frac{\mathrm{d}^{2} \rho_{A}}{\mathrm{~d} z^{2}}+\left(-r_{A}\right) \rho_{g R} \varepsilon \tau=0
$$

where, $u$ is the velocity of gas oil, $D$ is the diffusion coefficient, $\rho_{g R}$ is the total density of feed and products, $\rho_{A}$ is the density of gas oil, $\left(-r_{A}\right)$ is the rate of reaction.

But the density of reactant, $A$ is

$$
\rho_{A}=y_{A} \rho_{g R}
$$

where $y_{A}=$ mass fraction of gas oil.

Substituting Equation (3) into Equation (2) and assuming constant total mass density gives;

$$
\begin{aligned}
& \left(\frac{D}{u L_{R}} \frac{\mathrm{d}^{2} y_{A}}{\mathrm{~d} z^{2}}\right)-\frac{\mathrm{d} y_{A}}{\mathrm{~d} Z}-\tau\left(-r_{A}\right) \varepsilon=0 \\
& \text { But, } V_{R}=A_{R} L_{R} z \text { and } v_{o}=\frac{F_{g r} C T O}{\rho_{g R}}
\end{aligned}
$$

hence;

$$
\tau=\frac{A_{R} L_{R} z \rho_{g R}}{F_{g R} C T O}
$$

Substituting Equation (6) into Equation (4) gives;

$$
\left(\frac{D}{u L_{R}} \frac{\mathrm{d}^{2} y_{A}}{\mathrm{~d} z^{2}}\right)-\frac{\mathrm{d} y_{A}}{\mathrm{~d} Z}-\frac{A_{R} L_{R} Z \rho_{g R}}{F_{g R} C T O}\left(-r_{A}\right) \varepsilon=0
$$

Similarly, the basic material equations governing the yield of the cracking products gasoline (B), light gases (F) and coke (G) are expressed respectively as;

$$
\begin{aligned}
& \left(\frac{D}{u L_{R}} \frac{\mathrm{d}^{2} y_{B}}{\mathrm{~d} z^{2}}\right)-\frac{\mathrm{d} y_{B}}{\mathrm{~d} Z}-\frac{A_{R} L_{R} Z \rho_{g R}}{F_{g R} C T O}\left(-r_{B}\right) \varepsilon=0 \\
& \left(\frac{D}{u L_{R}} \frac{\mathrm{d}^{2} y_{F}}{\mathrm{~d} z^{2}}\right)-\frac{\mathrm{d} y_{F}}{\mathrm{~d} Z}-\frac{A_{R} L_{R} Z \rho_{g R}}{F_{g R} C T O}\left(-r_{F}\right) \varepsilon=0 \\
& \left(\frac{D}{u L_{R}} \frac{\mathrm{d}^{2} y_{G}}{\mathrm{~d} z^{2}}\right)-\frac{\mathrm{d} y_{G}}{\mathrm{~d} Z}-\frac{A_{R} L_{R} Z \rho_{g R}}{F_{g R} C T O}\left(-r_{G}\right) \varepsilon=0
\end{aligned}
$$

\subsection{Four-Lump Kinetic Model}

The four-lump Kinetic model as proposed by [14] [15] is illustrated in Figure 2.

The overall rake constant of reaction is $k_{1}+k_{2}+k_{3}$. The rate constant of over cracking is $k_{4}+k_{5}$ and the rate constant of by-product and residue obtained is $k_{2}+k_{3}$ from the cracking of gas oil kinetic model. The cracking of gas oil to gasoline, light gases and coke is a second-order reaction while the cracking of gasoline to light gases and coke is first-order reaction [9]. Thus, the reaction rates of gas oil, gasoline, light gases $\left(C_{1}-C_{4}\right)$, and coke respectively are given as:

$$
\left(-r_{A}\right)=k_{1} y_{A}^{2} \phi+k_{2} y_{A}^{2} \phi+k_{3} y_{A}^{2} \phi
$$




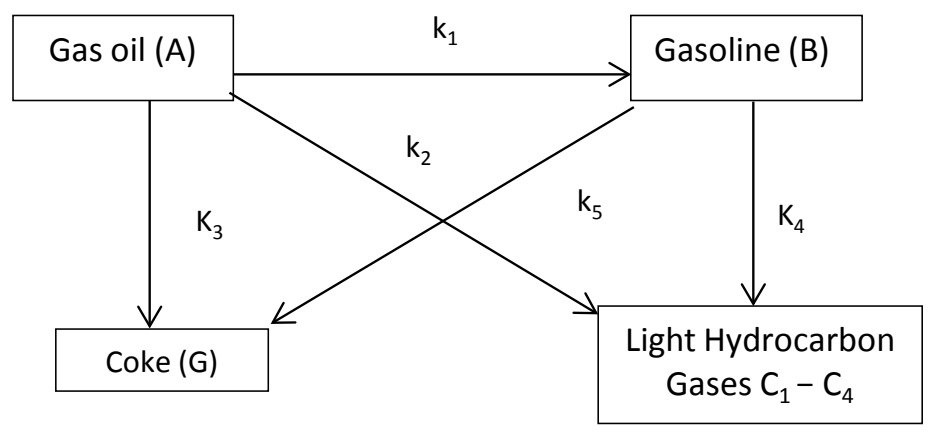

Figure 2. Kinetic scheme of four-lump model [14] [15].

Hence,

$$
\begin{gathered}
\left(-r_{A}\right)=\left(k_{1}+k_{2}+k_{3}\right) y_{A}^{2}=k_{o} y_{A}^{2} \\
\left(-r_{B}\right)=-k_{1} y_{A}^{2}+k_{4} y_{B}+k_{5} y_{B} \\
\left(-r_{B}\right)=\left[-k_{1} y_{A}^{2}+k_{B} y_{B}\right]
\end{gathered}
$$

where $k_{B}=k_{4}+k_{5}$

$$
\begin{aligned}
& \left(-r_{F}\right)=-k_{2} y_{A}^{2}-k_{4} y_{B} \\
& \left(-r_{F}\right)=-\left[k_{2} y_{A}^{2}+k_{4} y_{B}\right] \\
& \left(-r_{G}\right)=-k_{3} y_{A}^{2}-k_{5} y_{B} \\
& \left(-r_{G}\right)=-\left[k_{3} y_{A}^{2}+k_{5} y_{B}\right]
\end{aligned}
$$

Substituting Equations (12)-(15) into Equations (7)-(10) gives;

\section{GAS OIL (A)}

$$
\left(\frac{D}{u L_{R}} \frac{\mathrm{d}^{2} y_{A}}{\mathrm{~d} z^{2}}\right)-\frac{\mathrm{d} y_{A}}{\mathrm{~d} Z}-\frac{A_{R} L_{R} Z \rho_{g R}}{F_{g R} C T O} k_{o} y_{A}^{2} \phi \varepsilon=0
$$

\section{GASOLINE (B)}

$$
\left(\frac{D}{u L_{R}} \frac{\mathrm{d}^{2} y_{B}}{\mathrm{~d} z^{2}}\right)-\frac{\mathrm{d} y_{B}}{\mathrm{~d} Z}-\frac{A_{R} L_{R} Z \rho_{g R}}{F_{g R} C T O}\left[-k_{1} y_{A}^{2}+k_{B} y_{B}\right] \varepsilon=0
$$

\section{$\underline{C}_{1}-C_{4}-$ GASES (F)}

$$
\left(\frac{D}{u L_{R}} \frac{\mathrm{d}^{2} y_{F}}{\mathrm{~d} z^{2}}\right)-\frac{\mathrm{d} y_{F}}{\mathrm{~d} Z}-\frac{A_{R} L_{R} Z \rho_{g R}}{F_{g R} C T O}\left[-\left(k_{2} y_{A}^{2}+k_{4} y_{B}\right)\right] \varepsilon=0
$$

\section{COKE (G)}

$$
\left(\frac{D}{u L_{R}} \frac{\mathrm{d}^{2} y_{G}}{\mathrm{~d} z^{2}}\right)-\frac{\mathrm{d} y_{G}}{\mathrm{~d} Z}-\frac{A_{R} L_{R} Z \rho_{g R}}{F_{g R} C T O}\left[-\left(k_{3} y_{A}^{2}+k_{5} y_{B}\right)\right] \varepsilon=0
$$

The deactivation model for a deactivation order of $m$ equal to 1 as proposed by [17] is an exponential law of the form;

$$
\phi=\exp (-\alpha \tau)
$$

The deactivation constant, $\alpha$ in Arrhenius temperature dependent equation is determined by: 


$$
\alpha=\alpha_{0} \exp \left(-\frac{E_{\alpha}}{R T}\right)
$$

where $T=$ Reaction temperature, $\alpha=$ Catalyst decay constant, $\alpha_{0}=$ Pre-exponential constant for catalyst decay, $E_{\alpha}=$ Activation energy for catalyst deactivation, $R=$ Universal gas constant.

Substituting Equation (6) and Equation (21) into Equation (20) gives;

$$
\phi=\exp \left[-\alpha_{0}\left(\frac{A_{R} L_{R} Z \rho_{g R}}{F_{g R} C T O}\right) \exp \left(-\frac{E_{\alpha}}{R T}\right)\right]
$$

\subsection{Energy Balance Equation}

Applying the law of conservation of energy for a differential element of the reactor to the reacting species and the heterogeneous endothermic cracking reactions at steady state, the energy balance can be written mathematically as:

$$
\frac{\mathrm{d} T^{2}}{\mathrm{~d} Z^{2}}-\left(\rho_{g} u c_{p}+\rho_{s} u c_{p_{s}}\right) \frac{\mathrm{d} T_{R}}{\mathrm{~d} l}-\sum_{i=1}^{5} \rho_{g R} \varepsilon\left(\Delta H_{i}\right)\left(-r_{i}\right)=0
$$

where $\rho_{g}, \rho_{s}$ are the density of gas and catalyst respectively.

To express Equation (23) in dimensionless form, the following dimensionless parameters are defined: $\mathrm{d} z=\frac{\mathrm{d} l}{L_{R}}, \quad \mathrm{~d} T=\frac{\mathrm{d} T_{R}}{T_{\text {ref }}}$, and $\tau=\frac{L_{R}}{u}$ gives;

$$
\left(\frac{K T_{r e f}^{2}}{L_{R}^{2}}\right) \frac{\mathrm{d}^{2} T}{\mathrm{~d} Z^{2}}-\frac{\left(\rho_{g} c_{p_{g}}+\rho_{s} c_{p_{s}}\right) T_{r e f}}{\tau} \frac{\mathrm{d} T}{\mathrm{~d} Z}-\sum_{i=1}^{5} \rho_{g R} \varepsilon\left(\Delta H_{i}\right)\left(-r_{i}\right)=0
$$

where $T$ = dimensionless temperature, $T_{r e f}=$ reference temperature, $T_{R}=$ axial reaction temperature, $K=$ thermal conductivity, $c_{p_{g}} \& c_{p_{s}}=$ specific capacity of gas oil and catalyst respectively.

Substituting Equation (6) into Equation (24) gives;

$$
\left(\frac{K T_{r e f}^{2}}{L_{R}^{2}}\right) \frac{\mathrm{d}^{2} T}{\mathrm{~d} Z^{2}}-\frac{\left(\rho_{g} c_{p_{g}}+\rho_{s} c_{p_{s}}\right) F_{g r} C T O T_{r e f}}{A_{R} L_{R} z \rho_{g R}} \frac{\mathrm{d} T}{\mathrm{~d} Z}-\sum_{i=1}^{5} \rho_{g R} \varepsilon\left(\Delta H_{i}\right)\left(-r_{i}\right)=0
$$

Multiplying through by $\left(\frac{L_{R}^{2}}{K T_{r e f}^{2}}\right)$, Equation (25) becomes;

$$
\frac{\mathrm{d}^{2} T}{\mathrm{~d} z^{2}}-\frac{\left(\rho_{g} c_{p_{g}}+\rho_{s} c_{p_{s}}\right) F_{g r} C T O T_{r e f}}{A_{R} L_{R} z \rho_{g R}} \frac{\mathrm{d} T}{\mathrm{~d} Z}-\left(\frac{L_{R}^{2}}{K T_{r e f}^{2}}\right) \sum_{i=1}^{5} \rho_{g R} \varepsilon\left(\Delta H_{i}\right)\left(-r_{i}\right)=0
$$

But,

$$
\left(\Delta H_{i}\right)\left(-r_{i}\right)=y_{A}^{2}\left[k_{1}\left(\Delta H_{1}\right)+k_{2}\left(\Delta H_{2}\right)+k_{3}\left(\Delta H_{3}\right)\right]+y_{B}\left[k_{4}\left(\Delta H_{4}\right)+k_{5}\left(\Delta H_{5}\right)\right]
$$

Substituting (27) into (26) gives;

$$
\begin{aligned}
& \frac{\mathrm{d} T^{2}}{\mathrm{~d} z^{2}} \frac{-\left(\rho_{g} c_{p_{g}}+\rho_{s} c_{p_{s}}\right) F_{g r} C T O L_{R}}{A_{R} \rho_{g R} K T_{r e f}}-\frac{L_{R}^{2}}{K T_{r e f}^{2}} \sum_{i=1}^{5} \rho_{g R} \varepsilon \\
& \cdot\left(y_{A}^{2}\left[k_{1}\left(\Delta H_{1}\right)+k_{2}\left(\Delta H_{2}\right)+k_{3}\left(\Delta H_{3}\right)\right]+y_{B}\left[k_{4}\left(\Delta H_{4}\right)+k_{5}\left(\Delta H_{5}\right)\right]\right)=0
\end{aligned}
$$




\subsection{Materials}

The properties and compositions of feed and products of the industrial Fluid Catalytic Cracking process, the dimensions of FCC reactors, are presented in Table 1 and Table 2 respectively, the feedstock composition is given in Table 3, while the physical properties of the reacting species and catalyst are presented in Table 4.

\subsection{Solution Techniques}

The set of parabolic Ordinary Differential Equations (ODE) from the models were not amenable to analytic solution technique. The equations were solved numerically if all the parameters are known. The second order differential equations were reduced to first order differential equations by substitutions. The boundary value was converted into an initial-value problem and solved numerically using the fourth order Runge Kutta algorithm. Visual Basic 6.0 program was used to simulate the model.

Since gas oil cracked to the various products, the mass fraction of gas oil is 1 at $L_{R}=0$; while the mass fraction of the products at the inlet is zero. The boundary condition at the inlet of the reactor; mathematically is

$$
z=0\left\{\begin{array}{l}
y_{A O}=1 \\
y_{B O}=y_{G O}=y_{F O}=0
\end{array}\right.
$$

\section{Results and Discussion}

Table 5 shows the comparison between plant yields and predictions from model

Table 1. Feed and product properties of industrial FCC riser reactor [16].

\begin{tabular}{ccccc}
\hline Component & API Gravity & Specific Gravity & $\begin{array}{c}\text { Composition } \\
\text { Weight } \%\end{array}$ & Flow rate $(\mathrm{kg} / \mathrm{hr})$ \\
\hline Gas oil feed & 21.2 & 0.927 & 100 & 244,090 \\
Fuel gas & - & - & 5.4 & 13,181 \\
C3 LPG & - & - & 6.3 & 15,388 \\
C4 LPG & - & - & 10.7 & 26,118 \\
Gasoline & 60.0 & 0.739 & 45.9 & 112,037 \\
Light Cycle oil & 14.0 & 0.973 & 17.8 & 43,448 \\
Bottoms & 0.5 & 1.072 & 8.8 & 21,480 \\
Coke & - & - & 5.1 & 12,448 \\
\hline
\end{tabular}

Table 2. Dimension of industrial FCC riser reactor [16].

\begin{tabular}{cc}
\hline Parameter & Value $(\mathrm{m})$ \\
\hline Length & 22.9 \\
Diameter & 2.9 \\
Cyclone height & 14.24 \\
Cyclone diameter & 1.5 \\
Disengager height & 24.5 \\
\hline
\end{tabular}


Table 3. Feedstock composition (mass spectrometric method), \% Mass [16].

\begin{tabular}{ccc}
\hline Paraffins & Naphthenes & Aromatics \\
\hline 35.4 & 16.1 & 48.1 \\
\hline
\end{tabular}

Table 4. Physical properties of reacting species and catalyst [16].

\begin{tabular}{ccc}
\hline Parameter & Units & Value \\
\hline Vapour density & $\mathrm{kg} \cdot \mathrm{m}^{-3}$ & 9.52 \\
Liquid density at 2880 K & $\mathrm{kg} \cdot \mathrm{m}^{-3}$ & 924.8 \\
Specific heat of gas & $\mathrm{kj} \cdot \mathrm{kg}^{-1} \cdot \mathrm{K}^{-1}$ & 3.3 \\
Specific heat of liquid & $\mathrm{kj} \cdot \mathrm{kg}^{-1} \cdot \mathrm{K}^{-1}$ & 2.67 \\
Heat of vaporization & $\mathrm{kj} \cdot \mathrm{kg}^{-1}$ & 156 \\
Temperature of vapourization & $\mathrm{K}$ & 698 \\
-gas oil to gasoline & $\mathrm{kj}$ & -2970 \\
-gas oil to light hydrocarbon gases & $\mathrm{kj}$ & -9240 \\
-gas oil to coke & $\mathrm{kj}$ & 23,820 \\
-gasoline to light hydrocarbon & $\mathrm{kj}$ & -6030 \\
-gasoline to coke gases & $\mathrm{kj}$ & 22,606 \\
\hline Catalyst & & \\
Bulk density & $\mathrm{kg} \cdot \mathrm{m}^{-3}$ & 975 \\
Particle size & $\mathrm{m}$ & $95 \times 10^{-6}$ \\
Specific heat capacity & $\mathrm{kj} \cdot \mathrm{kg} \cdot \mathrm{K}^{-1}$ & 1.12 \\
\hline Mass flow rate of catalyst from the reactor to regenerate & $\mathrm{kg} / \mathrm{hr}$ & $1,729,750$ \\
\hline
\end{tabular}

Table 5. Comparison of model predictions with plant data.

\begin{tabular}{cccc}
\hline Parameter & Plant Data & Model Prediction & Percentage Deviation \\
\hline Weight Fraction of Gas-oil & 0.266 & 0.2689 & -1.09 \\
Weight Fraction of Gasoline & 0.459 & 0.456 & 0.65 \\
Weight Fraction of Light Gases $\left(C_{1}-C_{4}\right)$ & 0.224 & 0.2233 & 0.31 \\
Weight Fraction of Coke & 0.051 & 0.0518 & -5.7 \\
Riser Outlet Temperature $(\mathrm{K})$ & 658 & 646.41 & 1.76
\end{tabular}

(Equations (16)-(19) and Equation (28)), indicating that the predicted data agree reasonably well with plant data. The results showed a deviation of $-1.09 \%$ for gas-oil, $0.65 \%$ for gasoline, $0.31 \%$ for light-gases, $-5.7 \%$ for coke, and $1.76 \%$ for the riser outlet temperature.

The model predicts a gas oil conversion of $73.1 \%$ and a yield of $45.6 \%, 22.33 \%$ and $5.18 \%$ for gasoline, light gases and coke respectively. The results showed that the mass fraction of gas-oil decreased, that is, conversion increased along the bed height. The yield of gasoline, Light gases, and coke increased but the yield of gasoline decreased from a height of $16 \mathrm{~m}$ due to its secondary cracking to form 
gases and coke predicated by higher temperature and catalyst deactivation as shown in Figure 3.

Figure 4 shows the temperature progression along the reactor height. Temperature decreased from the initial feed temperature of $800 \mathrm{~K}$ to outlet temperature of $646.41 \mathrm{~K}$. Heat was absorbed during catalytic cracking of vacuum gas oil indicating that the cracking reaction was endothermic.

\section{Reactor Simulation}

A simulation model can be used to optimize plant performance by choosing the optimal set of operating condition such as temperature, pressure, flow rate etc. in this section a sensitivity analysis was performed to determine the effects of certain process variables on the performance of the model developed.

\section{1) Variation of Vessel Dispersion Number}

The vessel dispersion number measures the level of deviation from plug flow assumption. It is the ratio of the dispersion coefficient to the product of the superficial velocity and the reactor length. The dispersion number decreased with an increase in reactor length. Hence, the reactor flow pattern tends to plug flow which is characterized with an increase in the yield of products. Figure 5 depicts the effect of the variation of vessel dispersion number on the mass fraction of gas-oil, yield of gasoline, light gases, and coke along the reactor length.

As shown in Figure 5, the mass fraction of gas oil decreased with increase in Vessel Dispersion Number. Yields of light gases, gasoline and coke increases with vessel dispersion number.

\section{2) Variation of Catalyst to Gas-Oil Ratio (CTO)}

The effect of catalyst to gasoil ratio (CTO) on the mass fraction of gasoil, gasoline, gases and coke is depicted in Figure 6. Increasing the CTO means increasing the flow rate (quantity) of catalyst entering the reactor. More catalyst is available for the reaction, thus increasing the active sites available for the cracking reactions. Increase in catalyst flow rate also entails an increase in the sensible

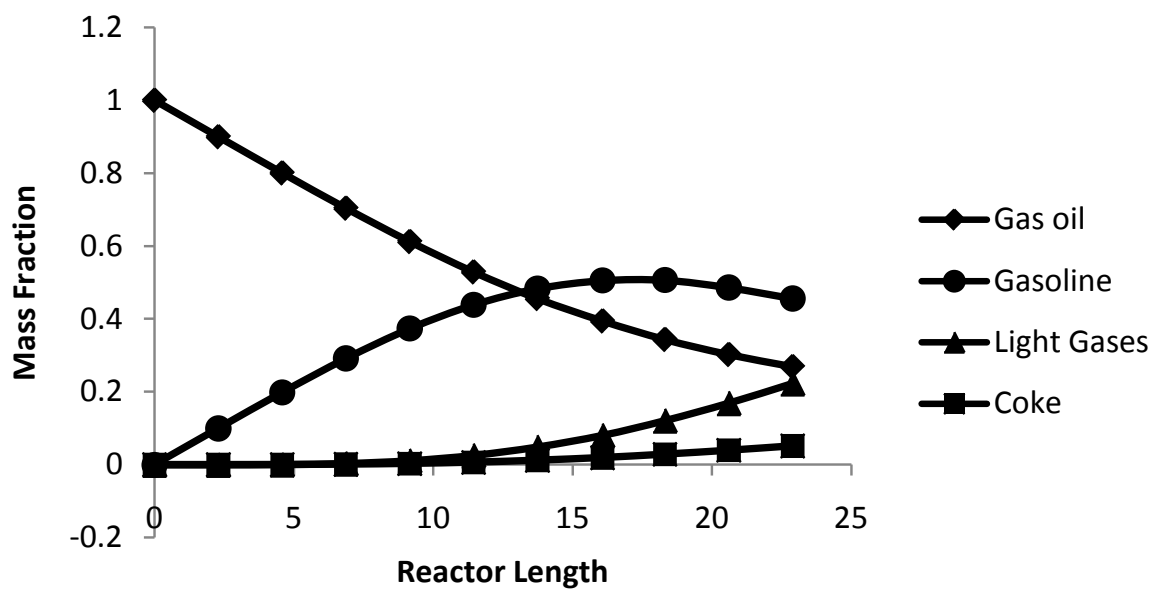

Figure 3. Variation of mass of gas-oil, gasoline, light gases, and coke, along reactor length. 


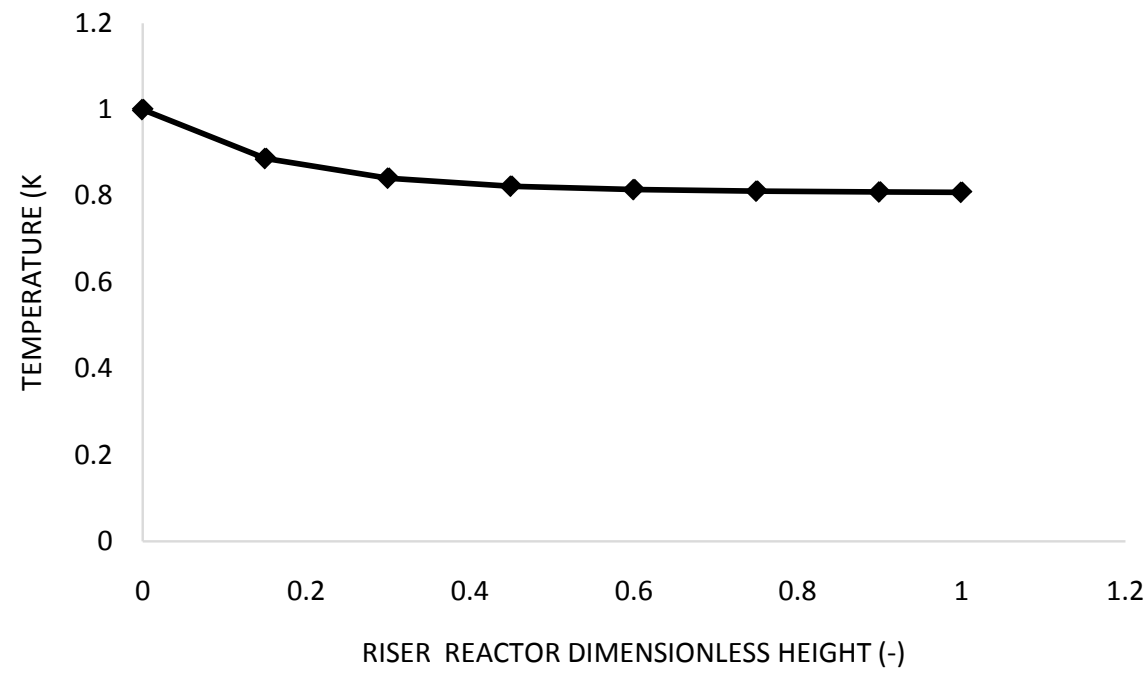

Figure 4. Variation of temperature along dimensionless height.

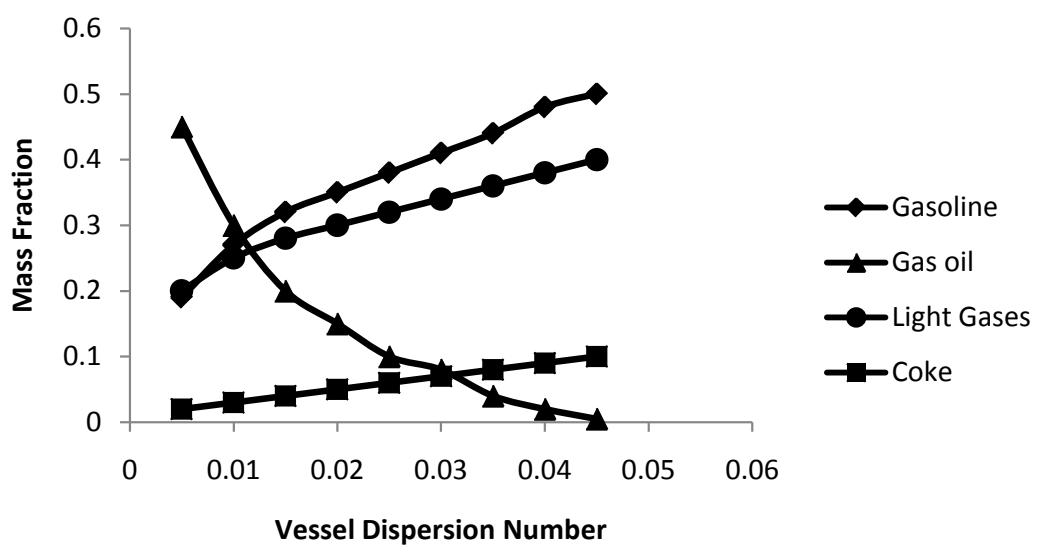

Figure 5. Effect of variation of vessel dispersion number, yield of gasoline, light gases and coke.

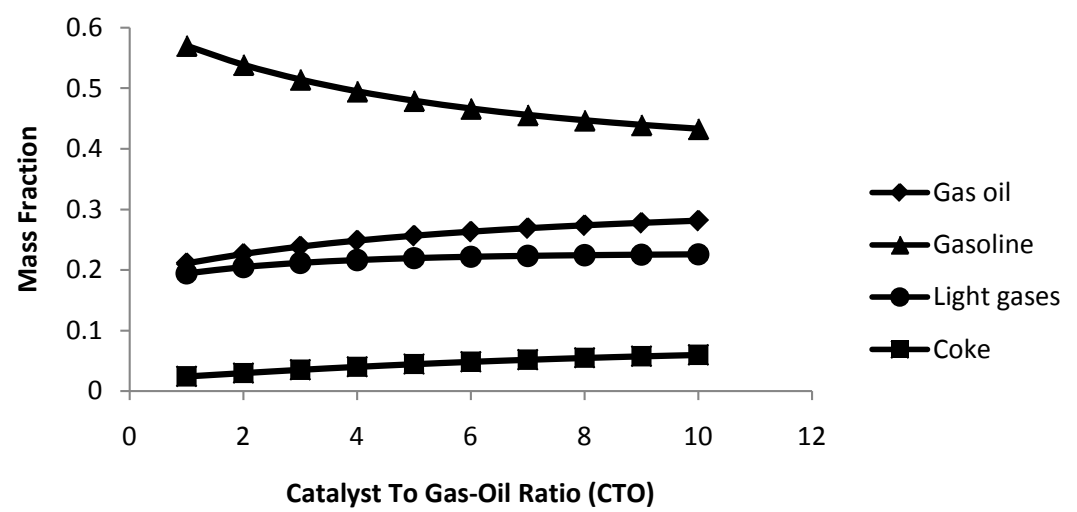

Figure 6. Effect of catalyst to gasoil ratio on yields of gasoline, light gases and coke.

heat associated with catalyst inflow, hence reactor temperature were higher and secondary cracking of gasoline occurred resulting in a sparing/gradual decrease in the yields of gasoline and corresponding gradual increase in the yields of gases 
and coke.

\section{3) Variation of Mass Flow Rate of Gasoil}

Figure 7 shows the effects of the mass flow rate of gas oil on yields of gasoline, light gases and coke.

The result showed significant effect of the mass flow rate on the mass fraction of gas-oil decreased (conversion increased) with increase in mass flow rate of gas oil. The yield of gasoline increased progressively while the yield of dry gases decreased but had a negligible effect on coke yield.

4) Variation of Mass Fraction of Gas-Oil with yields of gasoline at various

\section{flow rates}

Figure 8 shows the variation of mass fraction of gas-oil with yield of gasoline as the most desired product at various flow rates of gas-oil. The mass fraction of gas-oil decreased to $36 \%$ (conversion of $64 \%$ ) at reactor height of $14 \mathrm{~m}$ and remained constant up to $17.2 \mathrm{~m}$ before decrease. This indicated that at this stationary point, optimum yield of gasoline of about $48 \%$ - $51 \%$ was obtained before decrease at higher reactor height. The decrease might be due to catalyst deactivation.

5) Variation of Reference Temperature with mass fraction of gas-oil and yield of products

The inlet temperature of the feed affects the conversion of the feed. The feed have to attain a significant high temperature for proper atomization of the molecules, the volatility of the feed increases with an increase in the temperature. This favours the conversion of gas-oil. The effect of temperature on the conversion of gas-oil, yield of gasoline, light gases and coke are shown in Figure 9. The conversion of gasoil increased (mass fraction decreased) significantly from temperature of $650 \mathrm{~K}$ and above. Yield of light gases and coke also show significant increase with increase in temperature, while the yield of gasoline decreased due to secondary cracking to form light gases and coke. Also at temperature above $650 \mathrm{~K}$, the catalyst deactivates due to sintering effects.

\section{Conclusion}

A dispersion model that incorporates four-lump kinetic scheme for the simulation

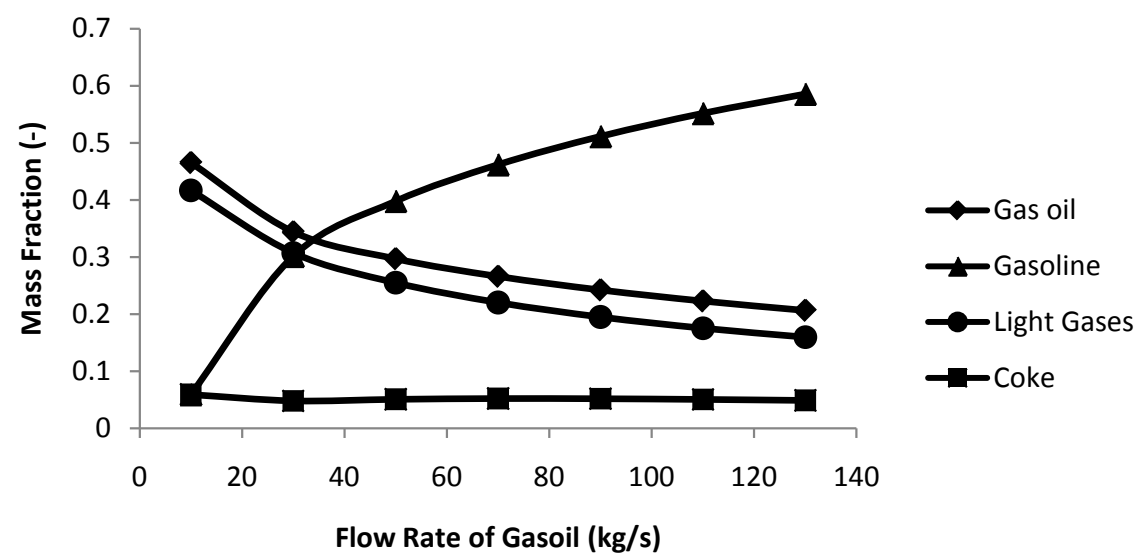

Figure 7. Effect of variation of flow rate of gas-oil, yield of gasoline, light gases and coke. 


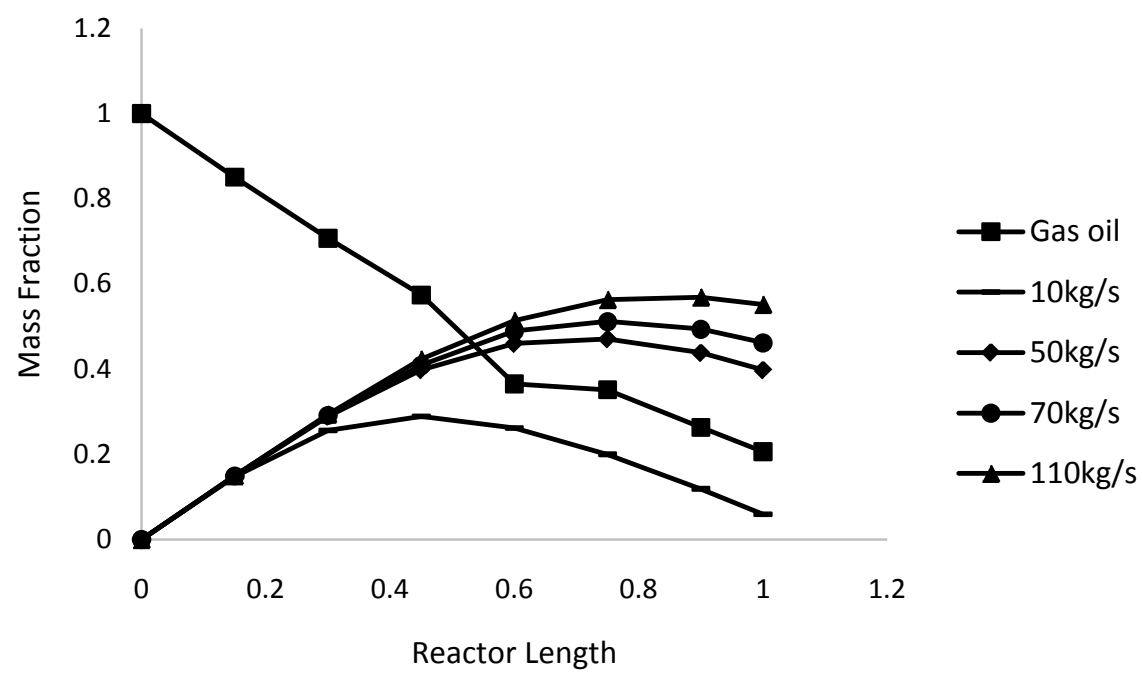

Figure 8. Variation of mass fraction of gas-oil with yields of gasoline at various flow rates along reactor length.

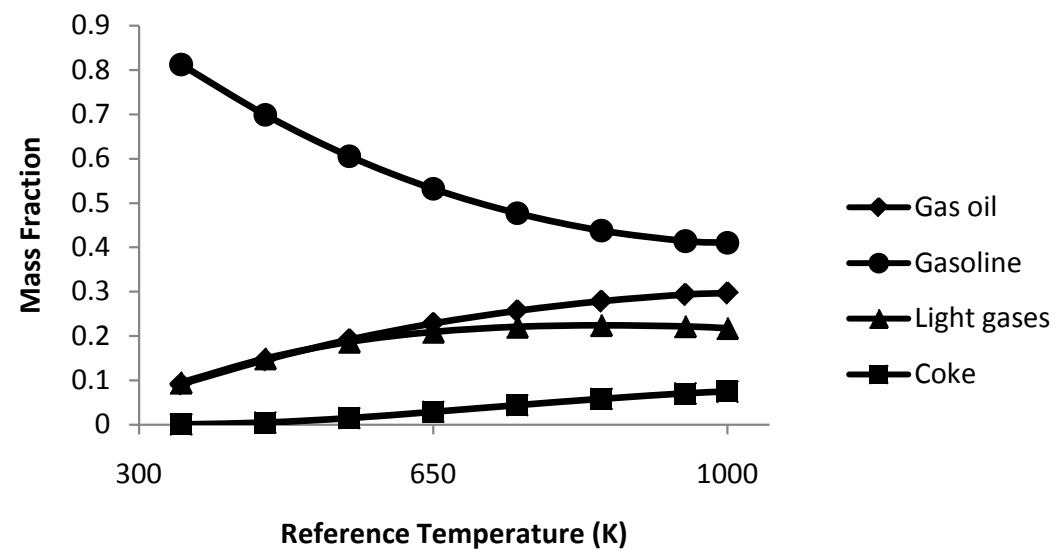

Figure 9. Effect of reference temperature on conversion of gas oil, yield of gasoline, light gases and coke.

of an industrial FCC riser reactor has been presented. The inclusion of dispersion number which represents the ideal flow pattern of the heterogeneous reactions that occur in the riser superimpose the oversimplification of previous researchers that assumed negligible dispersion. The results obtained from the model matched reasonably well with plant data with minimum deviation of -1.09 and maximum deviation of 1.76. Simulation results indicate that the vessel dispersion number, catalyst to gasoil ratio, reaction temperature and flow rate of gasoil are major process variables that affect the performance of FCC riser reactor.

\section{Conflicts of Interest}

The author declares no conflicts of interest regarding the publication of this paper.

\section{References}

[1] Hageberg, P., et al. (2002) Kinetics of Catalytic Cracking with Short Contact Times. 
Applied Catalysis A, 223, 73-84. https://doi.org/10.1016/S0926-860X(01)00744-X

[2] Bolkan, Y., Berruti, F., Zhu, J. and Milne, B. (2000) Modelling Circulating Fluidized Bed Downers. Powder Technology, 132, 85-100. https://doi.org/10.1016/S0032-5910(03)00059-7

[3] Affum, H.A., Mumuni, I.I., Appiah, G.K., Adzaklo, S.Y. and Addo, M.A. (2013) On the Conversion of Gas Oil in Fluid Catalytic Cracking Risers: Application of Residence Time Distribution (Rtd) Concept. International Journal of Scientific \& Technology Research, 2, 168-173.

[4] Palos, R., Gutiérrez, A., Arandes, J.M. and Bilbao, J. (2018) Catalyst Used in Fluid Catalytic Cracking (FCC) Unit as a Support of NiMoP Catalyst for Light Cycle Oil Hydroprocessing. Fuel, 216, 142-152. https://doi.org/10.1016/j.fuel.2017.11.148

[5] Dasila, P.K., Choudhury, I., Saraf, D., Chopra, S. and Dalai, A. (2012) Parametric Sensitivity Studies in a Commercial FCC Unit. Advances in Chemical Engineering and Science, 2, 136-149. https://doi.org/10.4236/aces.2012.21017

[6] Fernandes, J.L., Pinheiro, C.I.C., Oliveira, N. and Bibeiro, F.R. (2003) Modeling and Simulation of an Operating Industrial Fluidized Catalytic Cracking (FCC) Riser. Proceedings of the $4^{\text {th }}$ Mercosur Congress on Process Systems Engineering, Coasta Verde.

[7] Ahari, J.S., Farshi, A. and Forsat, K. (2008) A Mathematical Modeling of the Riser Reactor in Industrial FCC Unit. Petroleum and Coal, 50, 15-24.

[8] Ali, H., Rohani, S. and Corriou, J.P. (1997) Modeling and Control of a Riser Type Fluid Catalytic Cracking (FCC) Unit. Transactions of the Institution of Chemical Engineers, 75, 401-412. https://doi.org/10.1205/026387697523868

[9] Heydari, M., Ebrahim, H.A. and Dabir, B. (2010) Modeling of an Industrial Riser in the Fluid Catalytic Unit. American Journal of Applied Sciences, 7, 221-226. https://doi.org/10.3844/ajassp.2010.221.226

[10] Oboho, E.O., Akpa, J.G. and Dagde, K.K. (2002) Modelling of a Fluid Catalytic Cracking (FCC) Riser Reactor the Four-Lump Model. Journal of Modelling, Design and Management of Engineering Systems, 1, 39-52.

[11] Alsabei, R.M. (2011) Model Based Approach for the Plant-Wide Economic Control of Fluid Catalytic Unit. PhD Thesis, Loughborough University, Loughborough.

[12] Dagde, K.K. and Puyate, Y.T. (2012) Six-Lump Kinetic Modeling of Adiabatic Plug-Flow Riser-Reactor in an Industrial FCC Unit. International Journal of Engineering Research and Applications, 2, 557-568, 557.

[13] Levenspiel, O. (2001) Chemical Reaction Engineering. 3rd Edition, John Willey \& Sons, Singapore.

[14] Lee, L.S., Chen, V.W. and Huang, T.N. (1989) Four-Lump Kinetic Model for Catalytic Cracking Process. Canadian Journal of Journal of Chemical Engineering, 67, 615-623. https://doi.org/10.1002/cjce.5450670414

[15] Yen, L.C., Wrench, R.E. and Ong, A.S. (1987) Reaction Kinetic Correlation for Predicting Coke Yield in Fluid Catalytic. $8^{\text {th }}$ Annual Fluid Catalytic Cracking Symposium, Budapest Hungary, 71-77.

[16] NPHRC (1987) Operating Manual of Fluid Catalytic Cracking Unit. New Port Harcourt Refining Company Vol. 1, Alesa-Eleme, Rivers State, Nigeria.

[17] Ancheyta-Juarez, J. and Satelo, R. (2002) Kinetic Modelling of Vacuum Gas Oil Catalytic Cracking. Journal of the Mexican Chemical Society, 46, 38-42. 